\title{
Aprender por aprender História: experiência e expansão da vida
}

\section{Learn just to Learn History: Experience and Expansion of Life}

\author{
Lucas Victor Silva* \\ Nilton Mullet Pereira** \\ Marcello Paniz Giacomoni ${ }^{* * *}$
}

\section{RESUMO}

Este artigo consiste em uma elaboração teórica sobre a aprendizagem histórica, provocada por uma experiência de sala de aula e pela inquietação dos autores sobre as relações com o passado ensejadas por uma aula de História. O relato de aula incorporado ao texto diz respeito ao modo como pensamos, a partir do conceito de experiência em Larrosa e de pensadores da diferença como Foucault, Nietzsche e Bergson, a aprendizagem histórica. O relato da aula foi o ponto de partida para problematizar a narrativa histórica e a crença demasiada na linguagem falada e escrita como formas de dar sentido ao passado. Pensamos que a aprendizagem histórica incorpora um aprender por aprender e uma aprendizagem ética e estética com a experiência. Palavras-chave: aprendizagem histórica; ensino de História; experiência.

\section{Abstract}

This article is a theoretical elaboration about the historical learning, caused by an experience in class and by the authors concern with the relationship with the past allow by a History class. This way, the class account in the text is about the manner we think the historical learning, from Larrosa's experience concept and from philosophers like Foucault, Nietzsche and Bergson. The class account have been the start to problematize the historical narrative in class and the strong belief in the spoken and written language as a manner to give sense to the past. We think the historical learning incorporates a learn just to learn and an ethical and aesthetic learning with the experience.

Keywords: experience; historical learning; History teaching.

\footnotetext{
* Universidade Federal Rural de Pernambuco (UFRPE), Recife, PE, Brasil. lucasvictor.ufrpe@ gmail.com

** Universidade Federal do Rio Grande do Sul (UFRGS), Porto Alegre, RS, Brasil. marcello. giacomoni@gmail.com.

*** Universidade Federal do Rio Grande do Sul (UFRGS), Porto Alegre, RS, Brasil.nilton.mullet@ ufrgs.br.
} 
Este artigo nasce de um certo enfado e de uma urgência. Enfado com a indiferença em relação à diferença e seu potencial ético e político. Urgência de uma aprendizagem histórica que valorize o acúmulo das experiências estranhas e que, desse modo, suponha uma aprendizagem, talvez pela primeira vez desde o século XIX, sem a utilidade que a tem feito reconhecer um passado morto diante de um presente soberbo e soberano. Uma aprendizagem da experiência e uma aprendizagem com valor estético.

Vivemos numa época de desencanto com a vida, quando o lucro e o dinheiro parecem oferecer todos os limites da experiência. Dessa maneira, esquecemos o valor de uma estética do existir, de uma arte de viver, de uma boa história contada sobre como os Yanomami constroem relações com o sonho ou com a floresta (Kopenawa; Albert, 2015), ou sobre como pessoas negras da cidade de Porto Alegre criaram práticas sociais, pensamento e práticas culturais que produzem existências singulares e experiências históricas baseadas em valores como circularidade, ludicidade e ancestralidade. De cima a baixo, dos mais altos graus da administração pública até os confins do nosso cotidiano, é o lucro e a utilidade que estabelecem os nossos modos de viver e de se relacionar, inclusive com o passado e com os outros povos. Por isso, muitas vezes as histórias que contamos parecem ter um elemento utilitário na chamada vida prática, algo que, obviamente, nunca conseguimos demonstrar ou explicar. Como a força significativa que leva um estudante do $6^{\circ}$ ano a indagar permanentemente seu professor de História sobre, por um lado, o valor da arte para a humanidade ou, por outro, por que a humanidade precisa de arte, o que na leitura do aluno parece ser desnecessário. Também por isso a célebre pergunta sempre nos importuna: "Professor, para que temos que aprender História?". Ou a terrível questão com a certeza implícita: "Mas, professor, para que eu vou estudar História, se não serve para nada?”. Ambos questionamentos decorrem desse imperativo do lucro. Ele faz ver apenas o que é lucrativo, nunca o que expande a vida, nunca o que nos dá um indecifrável gosto. A armadilha que reserva a afirmação e o questionamento leva o professor a procurar onde está essa utilidade e como demonstrá-la aos estudantes.

Ora, a História lida com os imaginários que produzimos sobre o passado, aborda as representações que diferentes sociedades fizeram sobre si mesmas e sobre outras, opera com a própria criação de conceitos que irão procurar dar sentido ao real. Mas ela não se confunde com o real; ela é um exprimível, um 
incorporal (Deleuze, 1998) que se cria desde os encontros de corpos, desde os estados de coisas. Qualquer tentativa, portanto, de responder à citada pergunta ou questionar a afirmação de que História não serve para nada só pode levar ou a um empirismo infantil, ou à afirmação de um presentismo e um utilitarismo que desqualifica o conhecimento histórico e o direciona para um uso identificável no mundo material. A História serve para violentar o pensamento (Deleuze, 2009), e isso implica tanto uma problematização do presente como uma provocação estética que envolve gosto e fruição. Mas, sobretudo, ambas ensejam uma aprendizagem da experiência.

A sociedade do lucro parece permitir muito pouco à experiência. Larrosa-Bondía (2002) lembra que o tempo em que vivemos é o tempo da opinião, de uma espécie de pressa que nos obriga a ter posição sobre tudo, sobre todas as coisas, de tal forma que esse modo de viver apressado não nos permite ser tocados e afetados pelos acontecimentos - logo, nada nos acontece. Nessa perspectiva, pensamos que a aula de História, provocativa e aberta aos acontecimentos, pode ensejar experiências, mas, para tanto, precisa se afastar do lucro, da utilidade e da rapidez das opiniões.

Isso nos leva a supor uma aprendizagem com valor estético. Trata-se de uma aprendizagem destacada desse presentismo que envolve de maneira tirana a diversidade de temporalizações imagináveis (também as inimagináveis), reduzindo o tempo ao que se pode ver no presente. A ideia de um aprender por aprender decorre de um conceito de aprendizagem que se vale dos afetos, do amor e da passividade, quando aprender não significa saber medir o tempo em pedaços, mas expandir a vida (Nietzsche, 2005). A referência que fazemos ao amor e à passividade está relacionada à noção de amor cortês (Pereira, 2009), forma concebida no âmbito da poesia trovadoresca do sul da França, na Idade Média, mais precisamente no século XII. Essa forma de amor profano se caracterizava por uma série de elementos, dos quais enfatizamos a busca do cavaleiro pela virtude. $\mathrm{O}$ amante se colocava em absoluta abertura diante da sua amada, e essa abertura significava abandonar sua própria identidade para poder estar apto a merecer o amor da Dama. Os obstáculos que se apresentavam ao amor dos dois tornavam o cavaleiro cada vez mais virtuoso para merecer o amor da amada. Portanto, padecer e ser paciente eram os elementos chaves da relação amorosa. E é esse padecimento que é disposição para aprender, para se deixar tocar e afetar pelos acontecimentos. Logo, o que compreendemos por 
aprender por aprender não consiste em uma neutralidade ingênua, mas um modo de contestar os "homens da mercadoria", que veem no lucro e na utilidade a única forma de se relacionar com os outros e com o mundo. A ideia é inserir no campo da aprendizagem histórica, não a imparcialidade, mas a estética e a ética: a primeira consiste em um movimento amoroso de padecimento diante do outro, a fim de permitir o diálogo e a aprendizagem; e a segunda consiste em, uma vez no centro do diálogo e da aprendizagem com o outro, poder olhar para si mesmo, num "cuidado de si” que permite a transfiguração do sujeito diante do que aprende. Isso porque o homem branco, do lucro e da mercadoria, somente olha narcisicamente para o outro, reduzindo-o a sua própria narrativa, aprisionando-o no seu discurso. E é isso o que a aula de História tem feito desde muito tempo. Eis um elemento central para a nossa aprendizagem como professores de História: como, de uma só vez, reconhecer a nossa branquitude narcísica, sempre narcísica, e problematizar a nós mesmos no sentido de ampliar nossas experiências com os passados alheios?

A obsessão por aproximar os conteúdos ensinados da realidade dos alunos não é uma novidade no campo da educação e, especialmente, no ensino de História. Um ciclo bem longo de produção conceitual e de pesquisa tem afirmado, sem qualquer oposição significativa, que a aprendizagem histórica tem dois elementos complementares: a necessária aproximação entre a História ensinada e a realidade dos alunos, o que implica selecionar conteúdo do entorno, como a história nacional ou a história local; e a necessária aprendizagem de conteúdos úteis para intervir na realidade e contrair relações de pertencimento, o que implica selecionar conteúdos relacionados aos pertencimentos identitários dos estudantes ou com evidente apelo político-identitário. Nessa perspectiva, um movimento bem significativo se pôs a repensar o ensino de História, sobretudo a partir do final dos anos 1980, tendo como elemento central a crítica à chamada história dos heróis e à afirmação do caráter político e ético da disciplina. A formação para a cidadania se tornou o elemento chave para se pensar o ensino. Do mesmo modo, ressaltou-se a importância das realidades dos alunos e de seus conhecimentos prévios. A ideia era pensar uma aula de História que aproximasse a realidade vivida da Ensinada. Esse movimento foi de extrema importância para o desenvolvimento do pensamento e da área do ensino de história. Este artigo quer agregar ao pensamento forjado pelos escritos de Elza Nadai (1984), Selva Guimarães Fonseca (1993) 
e Circe Bittencourt (2004), dentre muitos outros, ainda que procure ir em outra direção. Do mesmo modo, nos tempos atuais, muitos pensadores do campo têm se debruçado sobre a questão das identidades e procurado repensar os conteúdos, os temas e as práticas pedagógicas, considerando as relações de pertencimento pertinentes à sociedade brasileira.

Sem negar esses caminhos legítimos, este artigo se propõe a pensar de outro modo. A partir de uma perspectiva de aprendizagem histórica que considera o elemento do estranhamento e a experiência como chaves para a criação conceitual, que sugere que aprender não implica uma necessária relação do passado com o presente - ao contrário, que aprender significa abandonar, partindo de uma posição angustiante, o presente e a familiaridade como o limite desde onde se pode pensar. Nesse sentido, a ideia de ação sobre o presente diminui de relevo, e a noção de padecimento e passividade ganha contornos. Entretanto, seria ingênuo supor que aprender História não tem efeitos para a expansão da vida, inclusive no presente, logo, o caráter político, de intervenção social, de afirmação de existências é elemento vital de nossa perspectiva. $\mathrm{Pa}$ decer significa escutar, para aí poder entrar em diálogo, respeitando e aprendendo com a existência do outro. Tais possibilidades teóricas estão intimamente relacionadas à noção de pensamento de Deleuze (2005) e Foucault (2004) e à noção de experiência de Larrosa-Bondía (2002).

$\mathrm{O}$ texto que segue mistura amor e experiência, imaginação e fantasia, linguagem e corpo, num jogo entre identidade e alteridade como estratégia política para se ter experiência e se deleitar com o agudo sabor das histórias alheias. Por isso, partimos de uma aula-acontecimento-caos. Essa aula não pode ser confundida com uma tentativa de aproximar presente e passado, nem como uma investida para produzir efeitos de utilidade na vida prática. Em verdade, ela se revela como uma obra de arte, construída, vivida e partilhada com experiências diversas, de professores, de alunos e de pessoas com suas memórias e suas histórias.

Em 2018 o professor Marcello Paniz Giacomoni propôs uma sequência de aulas no Colégio de Aplicação da Universidade Federal do Rio Grande do Sul (UFRGS), em consonância ao "Novembro Negro na UFRGS", que desde 2017 unificou ações educativas e culturais de combate ao racismo na universidade. Tais aulas tiveram como proposta evidenciar a visibilidade e o protagonismo da população negra de Porto Alegre, bem como os próprios estudan- 
tes negros do Colégio de Aplicação e da UFRGS. A proposta consistiu em oferecer aos estudantes do $6^{\circ}$ e $7^{\circ}$ ano do ensino fundamental um diálogo em três atos: a cidade, o jogo e as pessoas.

Na segunda-feira, dia 5 de novembro de 2018, os estudantes realizaram uma saída de campo a quatro pontos do Museu de Percurso do Negro de Porto Alegre, todos localizados na área central da cidade. Todos também "escondidos" dentre marcas da memória das elites locais, e reafirmados a partir de obras de arte criadas pelo referido museu. Os alunos iniciaram no Mercado Público de Porto Alegre, um prédio neoclássico que é marca do centro vivo da cidade, e que também abriga em seu interior o assentamento do Orixá Bará, sendo um importante local de culto para as religiões de matriz africana, especialmente o Batuque. Depois passaram pela Praça da Alfândega, cercada por prédios de poder (bancos, antiga alfândega, museus), mas marcada pela obra da "Pegada africana", rememorando a presença da população negra naquele espaço (as quitandeiras, em especial). Em seguida foram à Igreja das Dores, construída com mão de obra escravizada, onde outrora, em frente, existia o pelourinho da cidade. Puderam, neste momento, por uma destas alegrias do acaso, acompanhar um ritual do Batuque, um culto a Oxalá, com autorização dos responsáveis pelo espaço e de forma tranquila. Terminaram na Praça Brigadeiro Sampaio, que homenageia o patrono da Infantaria do Exército Brasileiro. Para além da memória oficial, era neste espaço que se encontrava a forca, até meados de 1850. Estima-se que a ampla maioria dos enforcados neste local foram negros escravizados. Mas, para além da dor, os idealizadores do Museu de Percurso do Negro marcaram este espaço com um objeto de mais de 2 metros de altura: um tambor. Dotado de grande valor simbólico para as culturas africanas e afro-brasileiras, associado à vida e à ligação com o mundo espiritual, e presente em diversas práticas culturais da população negra, o percurso finalizou com essa singela ode à transformação: de um lugar de morte e sofrimento, para um lugar de vida. Eis o que entendemos como uma aprendizagem pela experiência. Deixar escorrer das bordas do tempo - de todas as dimensões de passado, presente e futuro - práticas sociais, modos de vida, estranhamentos e pertencimentos, num jogo que faz o estudante ter um respeito silencioso e pacífico em relação ao que vê, ao que houve, mas sobretudo ao que experimenta. Nenhuma utilidade, nenhum lucro à vista, apenas o gosto e a ética de se deixar afetar por mundos que aqueles estudantes nunca haviam visto, ainda 
que estivessem ali desde muito, mas ofuscados pelo narcisismo dos "homens da mercadoria”, nós mesmos que fizemos da nossa aula de História o lugar das narrativas autorizadas.

Na quarta-feira, dia 7 de novembro, os estudantes jogaram o jogo de tabuleiro “As viagens do tambor". ${ }^{1}$ Criado entre 2016 e 2018 por uma equipe interdisciplinar organizada pelo Laboratório de Ensino de História e Educação da UFRGS com participação vital de pessoas dos movimentos sociais negros da cidade, o jogo é baseado em uma mecânica de descoberta de pistas, similar ao "Detetive", e a narrativa se desenvolve justamente no entorno do tambor da Praça Brigadeiro Sampaio. O jogo fabula que o tambor um dia se cansou de ser apenas visitado e decidiu sair pela cidade. Nesta viagem, três grupos de elementos se entrecruzam para constituírem narrativas: onde o tambor foi? (dentre onze territórios de presença negra); quem ele encontrou? (dentre onze personagens da cultura negra); e o que ele está fazendo? (dentre seis práticas culturais da população negra). O tabuleiro, disposto na forma de um círculo de territórios (que não se relacionam à geografia e à temporalidade "reais" de Porto Alegre), propõe que os alunos interajam em roda, evidenciando o valor da circularidade. Personagens de variadas épocas percorrem espaços também de variadas épocas. Príncipe Custódio, falecido no início do século XX, pode interagir com o Mestre Borel. Podem também circular no Rubem Berta, bairro da periferia de Porto Alegre, e passar pela Ilhota, área de presença da população negra cuja urbanização da cidade suprimiu em meados do século XX. Podem praticar a ancestral capoeira, e também assistir ao recente Sopapo Poético. Um jogar que produziu e produz encontros que promovem aprendizagens, desfazendo memórias cristalizadas sobre a cidade, ao mesmo tempo que se abrem novas histórias. Fazendo uso da ludicidade e da brincadeira, o jogo objetiva produzir encontros, diálogos entre jogadores que acessam uma temporalidade e uma territorialidade muitas vezes diversas das habituais. O jogo se constrói como lugar de experiência e de criação. Ele proporciona encontros que têm como resultado pensar desde uma ética dos valores civilizatórios afro-brasileiros que, desse modo, ultrapassa os limites narrativos, explicativos e interpretativos, para uma aprendizagem simpática com a experiência. E o resultado de tais aprendizagens é o protagonismo, a visibilidade, o respeito, o conhecimento e o reconhecimento da vida dos povos negros. Mas também é um modo de uma dobra em relação a si mesmos. Nós, professores e alunos, 
pudemos olhar para nós mesmos, nossa ancestralidade, nossas relações comuns, a originalidade e a singularidade cultural e espiritual, os pertencimentos possíveis e, sobretudo, para nossa branquitude (Cardoso, 2010) e o modo como nos colocamos num lugar de privilégios, que produzem e mantêm a desigualdade. Eis a vida se expandindo e se fazendo com arte, passado e história.

Na quinta-feira, dia 8 de novembro, três das personagens negras do jogo foram convidadas para comparecer ao colégio para uma roda de conversa com os estudantes: a professora e pesquisadora Petronilha Beatriz Gonçalves e Silva, que foi a relatora da comissão que instituiu as Diretrizes Curriculares decorrentes da Lei $n^{\circ} 10.639 / 2003$, que trata do ensino da história e cultura africana e afro-brasileira nas escolas básicas; a Mestra Griô Elaine, guardiã de memórias da população negra da cidade de Porto Alegre, membro da Associação Mocambo, espaço de resistência e preservação da memória negra da cidade; e a coreógrafa, bailarina e produtora Iara Deodoro, ligada ao espaço Afro-Sul Odomodê, com larga atuação na cena artística negra da cidade. Elas puderam se apresentar, narrar suas relações com a cidade, com a educação, com os campos profissionais e, claro, com a negritude. Dispostas ao centro de um grande círculo de estudantes e professoras, foram ouvidas, foram questionadas, puderam responder; enfim, trocas foram produzidas.

Essa aula se deu em três atos: uma saída de campo que expôs aos estudantes um pouco das histórias e memórias da cidade de Porto Alegre, bem como com dos territórios negros da cidade; um jogo que provocou com seu mistério a criação de narrativas que propiciaram encontros inusitados e surpreendentes com vidas, culturas e lugares agora visíveis e prontos a criar novos sentidos; e por fim, encontros com mulheres negras, diríamos, heroínas ou personagens históricas da cidade, agora em pleno momento de simpatia com o tempo das alunas, num encontro de uma história viva, pulsante, criando efeitos estéticos para a aula e éticos para o modo como os estudantes irão construir suas próprias vidas e seus futuros.

Os encontros foram afirmativos. Fizeram produzir narrativas ainda não conhecidas ou catalogadas no mapa do turismo da cidade ou da aprendizagem histórica daqueles alunos e professores. Tornaram a aula um caos de pura criação desde a beleza da rua, passando pelo mistério do jogo e terminando com a arte do encontro com pessoas e suas histórias. Eis o que temos chamado de aprender por aprender e de aprendizagem histórica da experiência. Tratava- 
-se, antes, de um caminho que acessasse os afetos, talvez despretensiosamente e sem a sistematicidade com a qual habitualmente trata-se uma aula.

\section{A Perspectiva do Aprender POR Aprender}

A perspectiva de um aprender por aprender não se distancia de uma História ensinada que seja profundamente política e "de resistência", nem abandona o elemento ético como um modo profundo e significativo de aprender; ao contrário, aprofunda a problematização de si e do mundo desde um encontro com o outro.

A ideia de um aprender por aprender é profundamente politizada e constitui uma aprendizagem e uma postura ética na relação com o tempo e as temporalidades. Ainda que tal forma de aprendizado - que apresenta de uma só vez o espanto, a vertigem, o diletantismo e o gosto como práticas de aprendizagem que conduzem à possibilidade de se ter experiência com o outro - não esteja a ver, no conhecimento histórico, uma utilidade para a vida prática, ela se revela como forma suprema de uma estética da existência (Foucault, 2004), que afirma a vida como obra de arte (Nietzsche, 1992), dando contornos éticos e estéticos a uma aprendizagem que se move como ampliação dos limites do que existe. É então que a frugalidade, aliada ao espanto com o real, se revela como uma espécie de abertura por onde passam a experiência e o pensamento. Ela permite que algo nos toque e nos leve a pensar. Como afirma Nietzsche (1992, p. 5), somente como "fenômeno estético, a existência e o mundo aparecem eternamente justificados”. O gosto pelo estudo da História não consiste em uma atitude descompromissada com o mundo e com o futuro, ao contrário, é um esforço absurdo de ultrapassar os limites do lucro e da utilidade para pensar e ter experiência, elementos sem os quais as urgências do nosso presente se tornam naturais e intransponíveis. Ou seja, um espanto em relação ao presente do tempo, que aprisiona o sujeito em modelos, padrões e normas de conduta e que impõe limites ao que se pode ver e dizer. A frugalidade nos ajuda a não estar o tempo todo criando respostas às urgências do presente, reagindo e enfraquecendo nossa capacidade de pensar. Isso não quer dizer que as urgências do presente não sejam fundamentais para a aula de História, mas, dar conta delas e problematizá-las exige não estar preso a elas como se fossem o todo da vida. Nesse sentido, frugalidade tem a ver com pensamento, pois tal 
como considerava Arendt (2008), a ausência de pensamento não tem a ver com ter conhecimento formalizado ou mesmo contato com os problemas do presente, porque estar entregue aos padrões, modelos e clichês que o real constitui na atualidade dificulta os processos do pensar, nos mantém reativos e envolvidos, logo, incapazes de produzir novidades. Qualquer forma de resistência política, pedagógica, epistemológica precisa de arte, estética e fruição.

Uma estética da existência, como pensou Foucault (2004), permite acrescentar o elemento da experiência e da ética do cuidado de si em um espaço de encontros múltiplos, como a sala de aula de História. Na leitura de Foucault (2006) a construção de uma estética de existir implica o cuidado de si, razão pela qual o pensador se pôs a estudar as formas de técnicas de si no mundo grego, construindo uma história das relações do sujeito com a verdade. Foi a partir desses estudos que o filósofo pensou uma estética da existência ou uma amizade como modo de vida, uma vez que, na experiência grega, as relações de si para consigo mesmo estavam relacionadas a um jogo agonístico que implicava se autoconstituir, sem um elemento exterior que interdita e que limita. A interdição e o limite eram exatamente as características dos exercícios e técnicas de si no mundo moderno, no qual os elementos da interdição social, civil e religiosa eram definidores das relações de si consigo mesmos. Ora, isso quer dizer que, ao pensar uma aprendizagem histórica que inclua o elemento do cuidado de si sob a perspectiva foucaultiana, estaremos a pensar o modo como um sujeito pode se autoconstituir considerando uma relação de transfiguração com a verdade aprendida. Ou seja, verdade e espiritualidade são elementos inseparáveis para a filosofia antiga, retomada por Foucault desde seus estudos sobre a filosofia estoica. A aula de História requer, portanto, criar condições para um diálogo surdo entre saberes, conhecimentos históricos, fazeres, práticas sociais e cosmologias (Pereira, 2018b) a fim de deixar aberto o jogo das criações de futuros.

Desse modo, pensar que a História possa ser uma forma narrativa que nos apresenta possibilidades de experiência e deleite, gosto e fruição, implica pensar que o passado é muito mais do que aquilo que empregamos para lidar com o dia a dia. O passado é excesso em relação ao que recortamos para dar sentido ao cotidiano ou mesmo para escrever grandes narrativas históricas. A redução do passado à linguagem é uma questão muito delicada com a qual a História tem lidado, uma vez que é um recorte narrativo e de sentido no pas- 
sado. Essa redução leva a um relativismo que cria uma armadilha, bem como limita as possibilidades da experiência. Se o passado fosse apenas o que acionamos como lembrança para perceber o mundo atual ou somente o que selecionamos com documentos para depois produzir relatos históricos, o passado estaria identificado ao que dizemos dele ou à História, como discurso produzido sobre ele. Sem o elemento estético e sem a possibilidade de uma aprendizagem com a experiência, tanto o passado como a vida estariam limitados à prisão da narrativa. Entretanto, inserir o elemento da experiência no campo da História e na aprendizagem histórica significa, em primeiro, ter presente que ela é sempre uma narrativa que recorta o passado e lhe atribui sentido; em segundo, que tal operação pensada desde uma diferenciação entre passado e História e da suposição de que a experiência é muito mais do que a narrativa que produzimos, pode ser um modo de abrir o passado a múltiplas interpretações, oferecendo proficuidade ao processo criativo e potencializando o diálogo e a comunicação. Desse modo, pensamos como Paul Veyne (1995), quando afirma que em torno de todo fato histórico existe sempre um vazio, que lhe permite ser diferente. Isto é, o campo da experiência é um elemento vital que cria o vazio, que podemos chamar de virtual, como lugar de forças que dá produtividade à criação narrativa e às interpretações do passado. O pensamento precisa transbordar como acontecimento, de onde toda a experiência se torna possível. Sorrir, portanto, tem um papel mágico e místico na alegria de aprender História, sem ter que responder para si mesmo ou para outrem sobre as razões que fazem durar com os códigos do amor cortês ou com as tragédias de Alcibíades, por exemplo. A noção de acontecimento decorre da leitura de Deleuze dos estoicos. O acontecimento é o verbo que nunca perde a mobilidade, sobrevoa a superfície se desdobrando em passado e futuro, produzindo qualidades e sensações (Deleuze, 2007). Para o autor, o tempo indefinido do acontecimento é "a linha flutuante que só conhece velocidades, e ao mesmo tempo não pára de dividir o que acontece num já-aí e um ainda-não-aí, um tarde-de-mais e um cedo-demais simultâneos, um algo que ao mesmo tempo vai se passar e acaba de se passar" (Deleuze; Guattari, 2008, p. 48-49).

$\mathrm{O}$ acontecimento que se abate contra o clichê e contra a banalidade é um sorriso sem rosto, extraído do rosto que sorri, uma força-devir-sorriso cuja sina é sorrir, e sorrir é durar num tempo recuado em relação a qualquer rosto. Sorrir é uma qualidade pura, que envolve encontros nos quais nos perdemos 
de nossos rostos, de nossas identidades, para viver o puro acontecimento incorporal. Sorrir não depende de um rosto historicamente situado, como um estado de coisas "rosto que sorri", mas o sorriso como o que dura nos interstícios dos dispositivos que estabelecem o que se pode ver, falar e ser. O sorriso é um devir que nunca se estabiliza, ainda que linhas de individuação o efetuam aqui e acolá em um rosto, numa história, numa identidade. Fazer recuar o sorriso do rosto que sorri é uma operação que nos eleva à superfície de Aion, que nos entrega, em uma duração que se reparte indefinidamente entre passado e futuro. Deleuze (1998), na 23ª série de A lógica do sentido, nos apresenta Aion. Ele diz que Cronos compreende o tempo presente, sendo o passado e o futuro relativos ao presente, de modo que somente ele preenche o tempo, sendo futuro e passado sempre referidos e relativos ao presente. Este, como pensavam os estoicos, é o tempo das misturas de corpos, dos estados de coisas que vivem, desse modo, sempre no presente do tempo. Aion, por seu turno, constitui passado e futuro que, diferente do presente, que passa, insistem no tempo. Aion é, portanto, o tempo dos acontecimentos incorporais. Segundo Deleuze (1998, p. 171),

toda a linha do Aion e percorrida pelo instante, que não para de se deslocar sobre ela e faz falta sempre em seu próprio lugar. Platão diz muito bem que o instante é atopon, atópico. Ele é a instância paradoxal ou o ponto aleatório, o não-senso de superfície e a quase-causa, puro momento de abstração cujo papel é, primeiro, dividir e subdividir todo presente nos dois sentidos ao mesmo tempo, em passado-futuro, sobre a linha do Aion.

A experiência e o acontecimento dizem respeito a Aion, ainda que sua efetuação se dê no presente do tempo, sob a linha de Cronos.

Aprender História é, sim, uma operação da inteligência. Mas não é somente isso. Ela envolve uma espécie de padecimento que implica intuição (Bergson, 2010) e sensação. Logo, ainda que seja uma ciência, uma procura pela produção da verdade sobre o passado, ela não se afasta de uma arte que lhe doa todas as suas implicações éticas e estéticas. A aprendizagem se dá por uma espécie de violência (Deleuze, 2005) que nos leva a pensar, abandonando ou recriando antigas percepções ou certezas. Aprender se dá na atenção ao que se vê e ao que se fala, desde um interior das visibilidades e das enunciabilidades; mas esse interior é muito mais excessivo do que o que se pode falar ou ver, 
porque aprender também implica abrir esse interior a um exterior selvagem, turbilhonar, que é um caos genético, que se imiscui na cesura do ver e do falar, produzindo violências, afetos, e levando à criação e à aprendizagem.

\section{O Aprender por Aprender e o Acontecimento}

Uma coisa é ter o passado como experiência, outra coisa é tê-lo como objeto de uma narrativa. As duas formas de se relacionar com ele, que White (2018) chama de passado histórico e passado prático, respectivamente, constituem o cerne a partir do qual temos feito usos do passado, seja para tomar decisões no presente ou para pensar desde uma experiência alheia. Na esteira do que estamos pensando, uma dimensão da relação com o passado não exclui a outra, mas, no momento, queremos dar ênfase à segunda. White (2018, p. 16) afirma que

O passado histórico era o passado que poderia ser estudado cientificamente, desinteressadamente, como um fim em si mesmo e "para seu próprio fim". Idealmente - e este foi o gesto fundador científico da historiografia moderna - o passado histórico não era inquirido por qualquer motivo ulterior que não fosse a determinação sobre o que ele realmente consistia, de como entendia a si mesmo, o que nele havia ocorrido para lhe dar suas peculiares configurações, esboços e trajetórias de desenvolvimento.

A ênfase que damos ao passado prático é, justamente, o fato de ele incorporar o elemento da experiência, uma vez que se desprende e se liberta da narrativa, como racionalidade que forma e que define. Nesse sentido, pretendemos dar relevo à ideia de uma experiência com o passado pensado como duração (Bergson, 2005), e não como um antigo presente descrito e interpretado segundo as necessidades atuais.

O que nos interessa, portanto, é o conceito de experiência, a partir do conjunto de ensaios, artigos e conferências chamado Pedagogia profana, organizado por Jorge Larrosa (2005). O livro não constitui um projeto único, ou mesmo coeso. Sua organização é coerente com a abordagem indisciplinada, fragmentária, insegura, iconoclasta e crítica do discurso pedagógico dominante iluminista e tecnicista. 
Larrosa (2015, p. 9) se afasta da tradicional ideia de "formação" como "desenvolvimento integral e continuado de suas inclinações e possibilidades [...] [que] conduz à constituição de uma personalidade livre e integrada numa humanidade realizada". Tal concepção é tributária do ideal iluminista de uma personalidade harmônica e unitária, no qual o mundo tem um sentido que o organiza e o salva do caos e a escola é uma das responsáveis por ensinar esse sentido às novas gerações - ou seja, a ideia de que "formação" é dar forma (conformar segundo o modelo ideal de subjetividade burguesa) ao aluno disforme.

Para Larrosa (2015), não há um itinerário que leve a um si mesmo a ser descoberto, explorado ou realizado. O que somos está para ser singularmente inventado, criado, conquistado. Formar é ensinar a desaprender os esquemas interpretativos da tradição: o que deve ser dito, lido e visto. É ir "além de si mesmo" para chegar a "ser aquilo que se é".

Neste sentido, ele também repudia a ideia de que os objetivos pedagógicos são plenamente possíveis de serem conquistados, a certeza de que é possível ensinar de uma só maneira e fazer todos aprenderem. Reconhece-se a necessidade de modos de ensino diversos para dar conta de devires múltiplos presentes nas situações educativas.

O tempo da formação não é linear e cumulativo. O tempo daquilo que nos faz ser o que somos é um movimento que conduz à confluência de um ponto mágico de uma sucessão de círculos excêntricos que articulam uma rememoração temporal e um acontecimento presente. E esse ponto da confluência é inalcançável fora da imagem, da metáfora, do poético, do narrar (Larrosa, 2015).

Em outras palavras, o tempo da formação é o tempo da sucessão das experiências e acontecimentos. Em Pedagogia profana (Larrosa, 2015), a experiência emerge depois que algo acontece ao indivíduo e ele se coloca atento (distante) ao acontecimento. O acontecimento e sua atenção produzem a reflexão e a metamorfose/transformação do que o indivíduo é. A experiência acontece quando essa atenção permite o distanciamento dos esquemas usuais de percepção, das respostas arrogantes e mecânicas, e uma aproximação com o acontecimento, uma vez que ele o escuta, o observa e o sente. A transmutação, o renascimento, a conversão no que somos é provocada por momentos de perigo (os acontecimentos) que afetam o vivido, desorganizando-o e permitindo que trilhemos o nosso destino. Assumir o perigo é assumir o que 
sobra do acontecido (o trauma, a perda, a herança, a alegria, a reflexão) e recriá-lo, fazê-lo semente, trampolim e possibilidade de construir seu próprio caminho e, assim, renovar aquilo que se é. Esse movimento é a experiência.

Neste caminho, Larrosa busca demonstrar a noção da experiência em funcionamento no espaço-tempo da educação ao refletir sobre a leitura. $\mathrm{O}$ pensador acredita na experiência da leitura justamente porque ela é um espaço de realização do devir plural e criativo: "um movimento excêntrico, no qual o sujeito leitura abre-se à sua própria metamorfose" (Larrosa, 2015, p. 13). A experiência da leitura seria capaz de produzir uma formação sem prescrição ou modelo normativo e massificador. Entendidos como leitores, docentes e discentes podem se deixar levar pelas possibilidades da literatura, que contribuem para entender o que somos e continuar nos guiando, nos transformando e nos reinventando.

A leitura é entendida a partir de uma inversão: é o texto que lê o leitor, que o interpreta, que o interroga. É o leitor que pertence à obra. Neste sentido, o texto interpela o leitor para ser outro, afeta sua vida e o chama para ir além de si mesmo. Leitura é relação e não ação de um (leitor) sobre o outro (livro). E a experiência da leitura também é violenta, pois interrompe o já sabido, o estabilizado, o que se é. "O livro é aquilo que ensinou o leitor a ler o mundo poeticamente” (Larrosa, 2015, p. 111).

A leitura mistura o texto e o leitor: "ambos são líquido e podem misturar-se entre si. E o texto, uma vez liquefeito, embriagado e 'desmaternado', agora pode ser o elemento em que o leitor pode submergir para emergir transformado, o elemento líquido da metamorfose" (Larrosa, 2015, p. 108).

E o que é um leitor/aprendiz? Para Larrosa (2015, p. 109), é uma entidade em movimento, inacabada, em transe, ensimesmada, aguardando que a leitura acabe, que seus olhos retornem ao mundo e, então, possa se reconstituir em um novo eu. Ao emergir, ao levantar os olhos, livro e leitor são diferentes. $\mathrm{O}$ leitor, ao erguer o olhar, experimenta outra vez a força do esforço com que esse mundo e essa identidade foram modelados, assegurados e sujeitados a si mesmos. Além disso, experimenta a recuperação de si mesmo e de seu mundo como uma perda, como algo em que muitas coisas, talvez essenciais, desvaneceram-se irremediavelmente, tão sem remédio que sequer podemos saber o que eram.

Sobre a prática da leitura mediada pelo professor em situações educativas, 
Larrosa entende o texto como um presente, uma dádiva ou uma carta docente que se entrega aos leitores aprendizes. Mas é uma oferta que se manifesta em duas faces, pois o texto é composto de uma face exterior fixa, literal e homogênea para todos os leitores-estudantes e uma face interior que é múltipla, heterogênea, fragmentada e dispersa. A leitura é a articulação dessas faces pelo professor, na produção de um "sentido comum" por ele construído, que será multiplicado no silêncio e na palavra discente. Assim, "depois da leitura, o importante não é que nós saibamos do texto o que nós pensamos do texto, mas o que - com o texto, ou contra o texto ou a partir do texto - é o que sejamos capazes de pensar" (Larrosa, 2015, p. 142).

Desta forma, pensar a aprendizagem como experiência implica produzir atividades de ensino que permitam que os aprendizes se deixem afetar pelo acontecimento de cada conhecer e, assim, decidam aprender por aprender. E aprender consiste em perder-se da relação habitual com o presente, dessa relação que estabelece limites ao que se pode ter como experiência com o passado. Isso ocorre porque o acontecimento escapa à própria História; o que a História pode narrar consiste em uma efetuação do acontecimento, apenas isso; a qualidade de rejuvenescimento e envelhecimento (corte entre o passado e o futuro) do acontecimento não é disponível ao discurso histórico, aos estados de coisas que a História descreve. Mas ele é disponível para a aula de História, na forma do silêncio, da suspensão da narrativa e, sobretudo, na forma da provocação que desloca o presente para o jogo da energia vital de criação.

Essa disposição ao acontecimento é o que torna a sala de aula um lugar de experiência, uma vez que o lucro, o dinheiro e a utilidade cessam de regular as relações e a aprendizagem. Ora, Larrosa $(2015$, p. 27) mostra que o conhecimento, tal como nos relacionamos com ele, é "basicamente mercadoria e, estritamente, dinheiro; tão neutro e intercambiável, tão sujeito à rentabilidade e à circulação acelerada como o dinheiro". Larrosa nos lembra que tal concepção sempre remete a aprendizagem a algum tipo de restituição, e nunca a uma ampliação das possibilidades de vida, em uma aprendizagem solidária e aberta à experiência do outro.

Para compreender o que vem a ser um saber da experiência, será preciso abandonar, por ora, a própria noção de conhecimento construída pela ciência moderna, cartesiana, que o separou da espiritualidade e que fez desse uma 
mercadoria trocada, vendida, contrabandeada. Aprender a partir da experiência remonta aos estoicos, ao sonho Yanomami, aos valores afro-brasileiros e, neste momento, a uma pedagogia das encruzilhadas (Rodrigues Junior, 2018). Enfim, para Larrosa (2015, p. 27), entender o que é a experiência exige

remontar aos tempos anteriores à ciência moderna (com sua específica definição do conhecimento objetivo) e à sociedade capitalista (na qual se constituiu a definição moderna de vida como vida burguesa). Durante séculos, o saber humano havia sido entendido como um pátheimáthos, como uma aprendizagem no e pelo padecer, no e por aquilo que nos acontece. Este é o saber da experiência: o que se adquire no modo como alguém vai respondendo ao que vai lhe acontecendo ao longo da vida e no modo como vamos dando sentido ao acontecer do que nos acontece. No saber da experiência não se trata da verdade do que são as coisas, mas do sentido ou do sem-sentido do que nos acontece. E esse saber da experiência tem algumas características essenciais que o opõe, ponto por ponto, ao que entendemos como conhecimento.

A ideia de um aprender por aprender implica certa passividade, que nos leva ao passado desarmados dos preconceitos, mas também dos limites identitários e temporais que nos constituem. Aprender por aprender com o passado não visa excluir a potencialidade ética e política de tais aprendizagens, como já afirmamos diversas vezes; significa replicar o futuro no passado. $\mathrm{O}$ futuro como vitalidade virtual - ou seja, como forças, singularidades que povoam nosso olhar de fora - pode emergir como criação a partir dos encontros com o passado, uma criação de novas configurações, novos territórios. Trata-se, portanto, de não querer reduzir o passado ao presente, nem fazer o futuro uma projeção do presente como se este fosse mera continuidade do primeiro, mas de assistir ao espetáculo imprevisível de abertura para novos futuros. Para os Warlpiri, povo aborígene australiano mencionado por Pelbart (2000, p. 49), o futuro é como o sonho, onde passado, presente e futuro constituem estoques de todas as combinações possíveis "entre os elementos da existência”. É como se o sonho, para os Warlpiri, fosse uma camada virtual "que recobre o mundo concreto e que está com ele numa relação de troca permanente, de coalescência, de indiscernibilidade. Espécie de duplo, porém absolutamente real, que envolve os existentes atuais, recriando seus possíveis, liberando novos trajetos" (Pelbart, 2000, p. 49). 
Ora, um ensino que se permita aprender por aprender, que seja capaz de introduzir o elemento do espanto e da frugalidade no processo de aprendizagem, que se permita flertar com o Fora e que se envolva eticamente na construção de alternativas para o futuro, pode inserir novas temáticas, povos e experiências que não sejam tratados como o outro distante e suscetível ao valor moral de nossa narrativa, mas como outros estranhos que façam nascer diálogos ainda não pensados, encontros que permitam aprendizagem para expandir a vida. Nesse sentido, narramos anteriormente uma aula-acontecimento-caos a fim de demonstrar o modo como temos argumentado sobre a aprendizagem da experiência e sobre o aprender por aprender. Importante pensar que o que entendemos como Fora é uma pura potência criativa. Conceito que Foucault (2009) anuncia a partir de Blanchot e dos escritores modernos, como Mallarmé. Em O pensamento do exterior, Foucault pode pensar então em um ser da linguagem, como lugar onde coexiste a criação literária e cessam as funções representativas, comunicativas e de significação da linguagem, o que permite um lugar de criação distante de toda a prisão identitária ou subjetiva. Trata-se de pensar uma linguagem que não se diz relacionada aos seres do mundo ou destinada à prisão de um sujeito que representa, mas recuada em si mesma, em seu ser, uma linguagem pura. Desse modo, não há um sujeito que esteja no início de um ato de fala ou um objeto que seja referência do que se diz. O Fora se diz, portanto, desse "em si" da linguagem que insinua um pensamento depurado das coisas e das significações. A ideia de uma aula-caos foi usada no artigo "O que se faz em uma aula de História? Pensar sobre a colonialidade do tempo" (Pereira, 2018b), a partir de Nietzsche, a fim de problematizar os preconceitos, os pressupostos, as definições e as formas que consideram a aula de História apenas um lugar de transmissão e reconhecimento. Pensamos que uma aula de História é um espaço aberto, uma multiplicidade, acolhe temporalizações, memórias, sonhos, cosmologias, pessoas e surpresas imponderáveis e forças.

Pensar o passado a partir de histórias menores (Pereira, 2018a), por exemplo, corresponde ao pensamento de um tempo rizomático e ao aprender por aprender - duas situações relacionadas à aprendizagem histórica e que não negam a importância de uma aprendizagem através de disparadores do presente. Mas aprender é muito mais complexo e aberto do que fazer do passado uma interpretação útil ao presente, ou, por outro lado, reduzir o passado com 
base nas necessidades identitárias e políticas do presente - questões todas importantes politicamente na época em que vivemos. Não caberia, como já dito, medir o tempo em pedaços, mas efetivamente expandir a vida daqueles ali relacionados: alunos e alunas, professores e professoras, e mesmo as convidadas. Trata-se da aprendizagem como abertura, expansão da vida, acúmulo de energia, flerte com a energia vital, enfim, como experiência.

Aprender guarda, em si, o elemento indecifrável do silêncio - o silêncio que nos faz escutar o grito dos poetas-cantores galego-portugueses, de "menor categoria social", entoando cantigas de escárnio; o silêncio que faz aparecer Joana d'Arc, mulher e guerreira; o silêncio que nos mostra a insubordinação dos puros (cátaros); o silêncio que nos faz ouvir os gritos dos camponeses; o silêncio que rompe com a onipresença da Igreja e faz aparecer uma heresia como a albigense; o silêncio que abriga o grito dos poetas trovadores nordestinos, num ruminar da Idade Média em pleno Sertão; o silêncio que deixa escutar os ensinamentos da Mestra Griô Elaine; o silêncio que faz emergir o respeito pelos tambores do batuque. Enfim, é um silêncio que, deixando em seu rastro o mistério da aprendizagem, oferece encontros improváveis com o passado, afirma suas "pulsantes" experiências, deixando que se escutem as histórias menores e dando visibilidade aos resíduos que embaralham nossas concepções temporais.

Trata-se de um encontro com um passado que se constitui de múltiplos acontecimentos que compõem um mosaico turbilhonar e, por definição, não ordenado, permitindo encontros imprevisíveis que possibilitam aprendizagens inusitadas. Não se trata de voltar ao passado para "cultivar-se", para obter um acúmulo de erudição histórica (ainda que isso não seja algo de modo algum desprezível), mas para ter encontros - como dizia Deleuze (l'abécédaire..., 1996) —, estando "à espreita” e à espera de novos acontecimentos. Significa abandonar uma necessidade que o presente impõe de lembrar, utilizar, cultivar e fazer o passado se tornar o elemento de uma utilidade que, vez por outra, pode torná-lo nada mais do que uma projeção do próprio presente. Isso ocorre, via de regra, quando reduzimos o passado apenas aos interesses do presente, fazendo deste a chave para criar narrativas sobre o passado. Tal concepção não é nada estranha ao ensino de História, uma vez que desde os áureos anos 1980 e a revitalização do ensino de História crítico, temos vivido sob a urgência de pensar o passado submetido às respostas que precisamos achar para os 
problemas do presente. Pensamos que, ao contrário do que se possa supor, o potencial ético e político do estudo da história se mantém pulsante, mesmo quando procuramos aprender sobre o passado sem querer fazer dele a projeção do nosso presente e, ainda mais, quando um passado se dá sem qualquer relevância ou utilidade aparente, como se um estudo de um passado pudesse ser apenas um estudo sobre um passado, uma espécie de aprender por aprender. A experiência que apresentamos tem sim um papel ético e estético fundamental para pensar o presente e essa é a questão central. Mas consideramos que o que chamamos de aprendizagem da experiência e aprender por aprender possuem fortes efeitos para pensar o presente e os futuros; ainda que não partilhemos da gana lucrativa e da utilidade, aprender com o outro e com seus próprios referenciais identitários exige o mesmo desprendimento e passividade que nos permitem ser tocados pelos acontecimentos. Portanto, uma conversa com sujeitos históricos da cidade, um jogo e uma visita aos territórios negros da Porto Alegre, produzem sim efeitos, pois produzem visibilidades, problematizam o lucro que toda a história eurocêntrica buscou e questionam os modos narrativos a que estivemos identificados por muito tempo. Essa aula-experiência-caos é tanto elemento do pertencimento como a surpresa do estranhamento, ambos levam a um gosto e a um afeto que enseja uma aprendizagem histórica empática e simpática.

\section{Considerações Finais}

Podemos concluir, portanto, que uma aula de História se oferece à experiência quando provoca e prolifera acontecimentos. Se, como diz Larrosa (2015), algo nos acontece quando estamos abertos e pacientes, então o elemento da utilidade se torna estranho, uma vez que, como utilidade, ele está demasiado crente na linguagem e nos códigos que nos conduzem mais à cultura do que à natureza.

Ora, a narrativa histórica foi e é um dos modos através dos quais se deu o processo civilizatório. Ela, de certa maneira, nos inseriu no mundo da representação. Mas isso teve um preço bem caro. Se, por um lado, a filosofia moderna, sobretudo desde Descartes e, depois, Kant, fundou o modo científico de dizer o mundo, de ler a natureza, fundamentando a existência de uma forma de conhecimento que toma a natureza e a vida como objeto da operação 
das nossas representações, dos nossos conceitos, que se aproveitam da ausência para apresentar uma presença, por outro lado, essa estratégia representacional de relação com a natureza nos distanciou dela, nos deixou mergulhados na superficialidade do mundo da representação. Desse modo, nosso acesso ao "em si" da vida, à natureza, foi sempre mediado por códigos, e é por dentro dessa codificação que somos limitados a ver e entender a vida. É como se Apolo comandasse nossas ações e não nos desse a chance de retornar, em momento algum, aos braços de Dionísio.

Digamos que nos fizemos humanos, demasiado humanos e, desse modo, deixamos escapar a volúpia das forças da natureza. Mas, como historiadores e professores de História, sempre damos sentido histórico ao que pensamos, ao que dizemos e, inclusive, às metafísicas que criamos. É a radicalidade do sentido histórico o que nos permite, no contexto deste artigo, pensar uma aula de História na qual transitam os códigos, os conceitos, os nomes e as representações, enfim, a narrativa histórica, e é justamente ela que nos desloca para o plano de uma historicização da própria ideia e da própria operação realizada pela representação. Isso nos faz supor que aprender História não se limita à apreensão dos códigos, não se limita à definição dos conceitos. A disciplina, ao centrar sua atenção apenas na codificação do passado, perdeu o elemento da experiência. Essa crença demasiada na representação abandonou as forças que o passado possui para criar formas de vida. Ou seja, a obsessão pelas categorias e pelos processos não são, de modo algum, elementos impossibilitadores da aprendizagem, mas são, sem dúvida, elementos inibidores da experiência.

$\mathrm{O}$ retorno à natureza e à vida parece ser o elemento que falta, no refúgio da sala de aula, para constituir a complementaridade entre Apolo e Dionísio e, sobretudo, desmascarar nossa arrogância humanista e historiadora que, solta à sua própria sorte, solapa as forças vitais da criação e nos devolve apenas um mundo cifrado e exteriorizado de nós mesmos. Além da representação, do presente e suas urgências, estão as forças vitais que nos permitem sonhar e criar. Sem elas, somos sugados pelo mundo já definido, já dito, já individualizado, isto é, o mesmo; o mundo banal, em que temos nos debatido nestes últimos tempos.

Invocamos, portanto, as energias vitais de criação. Poder pensar desse modo tem sérias implicações. Ao abandonar a arrogância humanista em relação à natureza, e a arrogância da representação no seu deveras reducionista 
aprisionamento da realidade, nos tornamos frágeis, pacientes e inativos para poder aprender com as experiências alheias, como a dos povos negros da diáspora, que, no mais terrível e inimaginável sofrimento, criaram formas de vida e de relacionamento; ou a dos povos Yanomami, que, desde muito, têm sustentado um mundo na floresta, sempre ameaçada pelo avidez do lucro, da arrogância humanista e da lógica capitalística.

\section{REFERÊNCIAS}

ARENDT, Hannah. A vida do espírito: o pensar, o querer e o julgar. Rio de Janeiro: Civilização Brasileira, 2008.

BERGSON, Henri. A evolução criadora. São Paulo: Martins Fontes, 2005.

BERGSON, Henri. Matéria e memória: ensaio sobre a relação do corpo com o espírito. São Paulo: Martins Fontes, 2010.

BITTENCOURT, Circe (org.). O saber histórico na sala de aula. São Paulo: Contexto, 2004.

CARDOSO, Lourenço. Branquitude acrítica e crítica: a supremacia racial e o branco anti-racista. Revista Latinoamericana de Ciencias Sociales, Niñez y Juventud, Manizales, v. 8 n. 1, 2010. Disponível em: https://bit.ly/2CEaHFY. Acesso em: 10 dez. 2019.

DELEUZE, Gilles. Lógica do sentido. São Paulo: Perspectiva, 1998.

DELEUZE, Gilles. Foucault. São Paulo: Brasiliense, 2005.

DELEUZE, Gilles. Lógica do sentido. São Paulo: Perspectiva, 2007.

DELEUZE, Gilles. Diferença e repetição. Rio de Janeiro: Graal, 2009.

DELEUZE, Gilles; GUATTARI, Félix. Mil platôs. Capitalismo e esquizofrenia. Rio de Janeiro: Ed. 34, 2008. v. 4.

DORNELES, Maurício da Silva; GIACOMONI, Marcello Paniz; GIL, Carmem Zeli de Vargas; GOLEMBIEWSKI, Fernanda de Amorim; MEINERZ, Carla Beatriz; MOREIRA, Cristine Gubert; PEREIRA, Nilton Mullet; REIS, Stefany; VIEIRA, Daniele Machado. As viagens do tambor. Porto Alegre: Editora da UFRGS, 2018. Jogo de tabuleiro.

FONSECA, Selva Guimarães. Caminhos da história ensinada. Campinas: Papirus, 1993.

FOUCAULT, Michel. Ética, sexualidade, política. Rio de Janeiro: Forense Universitária, 2004. (Ditos e Escritos, V). 
FOUCAULT, Michel. A hermenêutica do sujeito. Tradução Márcio Alves da Fonseca e Salma Tannus Muchail. São Paulo: Martins Fontes, 2006.

FOUCAULT, Michel. O pensamento do exterior. In: MOTTA, Manoel Barros da (org.). Estética: literatura e pintura, música e cinema. Tradução Inês Autran Dourado Barbosa. 2. ed. Rio de Janeiro: Forense Universitária, 2009. p. 219-242. (Ditos e Escritos, III).

KOPENAWA, Davi; ALBERT, Bruce. A queda do céu: palavras de um xamã yanomami. São Paulo: Companhia das Letras. 2015.

LARROSA, Jorge. Pedagogia profana. Tradução Alfredo Veiga-Neto. São Paulo: Autêntica, 2015.

LARROSA-BONDÍA, Jorge. Notas sobre a experiência e o saber de experiência. Revista Brasileira de Educação, São Paulo, n. 19, p. 20-28, 2002.

L'ABÉCÉDAIRE de Gilles Deleuze. BOUTANG, Pierre-André. Paris: Vidéo 202; Éditions Montparnasse, 1996. Documentário (450 min.), sonoro, colorido, digital. Francês.

NADAI, Elza. A escola pública contemporânea: os currículos oficiais de história e o ensino temático. Revista Brasileira de História, São Paulo, v. 6, n. 11, p. 99-116, 1984.

NIETZSCHE, Friedrich. O nascimento da tragédia, ou Helenismo e pessimismo. Tradução, notas e posfácio J. Guinsburg. São Paulo: Companhia das Letras, 1992.

NIETZSCHE, Friedrich. Escritos sobre história. Apresentação, tradução e notas Noéli Correia de Melo Sobrinho. Rio de janeiro: Ed. PUC-Rio; São Paulo: Loyola, 2005.

PEREIRA, Nilton Mullet. Amor e interioridade no Ocidente Medieval: as cansos de Guilherme IX. Ler História, Lisboa, v. 57, p. 33-58, 2009.

PEREIRA, Nilton Mullet. Ensino de História e resistência: notas sobre uma História menor. @rquivo Brasileiro de Educação, Belo Horizonte, v. 5, n. 10, p. 103-117, 2018a.

PEREIRA, Nilton Mullet. O que se faz em uma aula de História? Pensar sobre a colonialidade do tempo. Revista Pedagógica, Chapecó, v. 20, p. 16-35, $2018 \mathrm{~b}$.

RODRIGUES JUNIOR, Luiz Rufino. Pedagogia das encruzilhadas. Revista Periferia, v. 10, n. 1, p. 71-88, 2018.

VEYNE, Paul. Como se escreve a história: Foucault revoluciona a história. 3. ed. Tradução Alda Baltar e Maria Auxiliadora Kneipp. Brasília, DF: UnB, 1995.

WHITE, Hayden. O passado prático. Tradução Arthur Lima de Avila, Mario Marcello Neto, Felipe Radünz Krüger. ArtCultura, Uberlândia, v. 20, n. 37, p. 9-19, 2018. 


\section{NOTA}

${ }^{1} \mathrm{O}$ jogo "As viagens do tambor" é um material pedagógico criado com trabalho coletivo coordenado pelo Laboratório de Ensino de História e Educação da UFRGS, que procura apresentar pessoas, territórios e práticas culturais das comunidades negras de Porto Alegre (Dorneles et al., 2018).

Artigo enviado em 09 de dezembro de 2019. Aprovado em 25 de janeiro de 2020. 